Provided for non-commercial research and education use. Not for reproduction, distribution or commercial use.

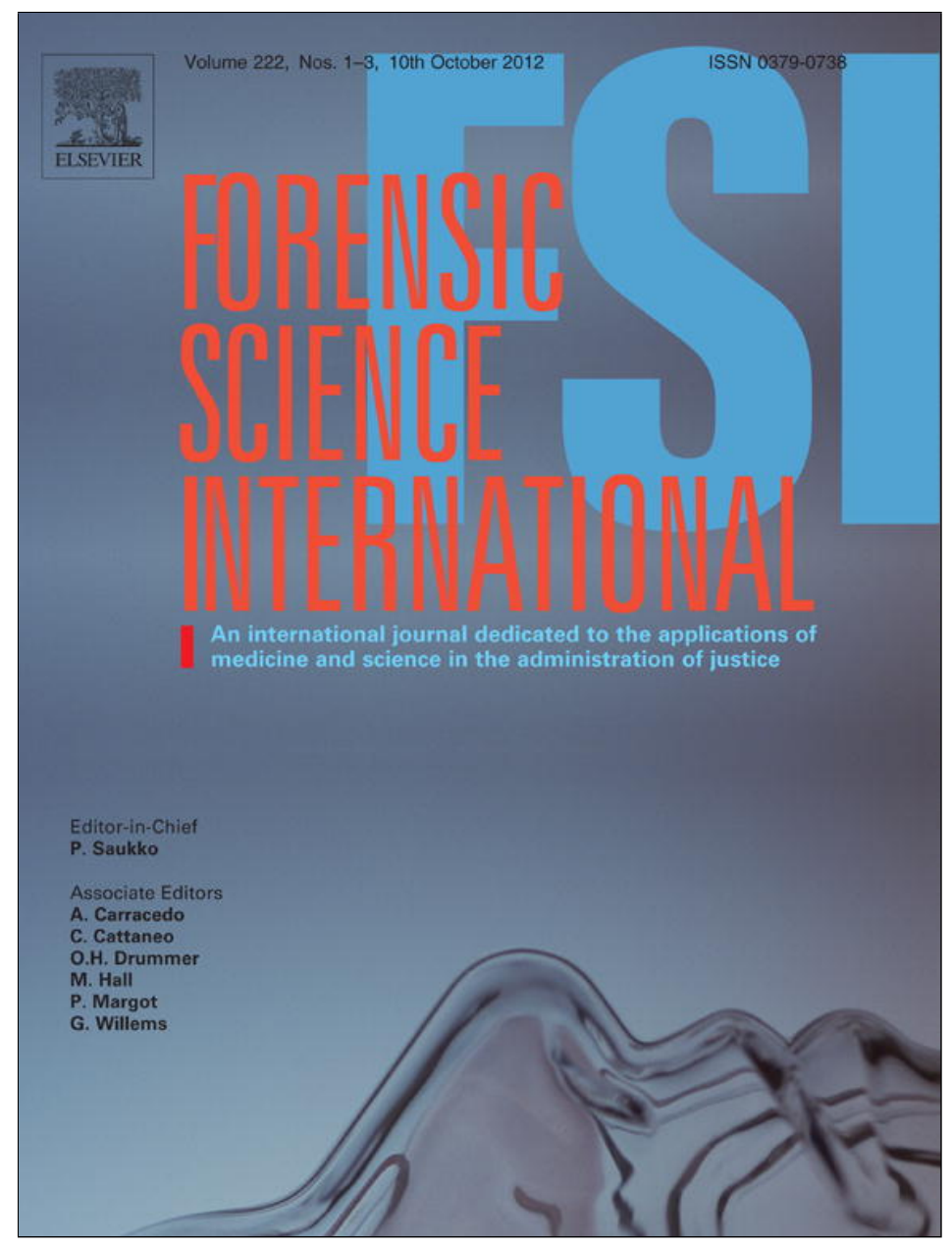

This article appeared in a journal published by Elsevier. The attached copy is furnished to the author for internal non-commercial research and education use, including for instruction at the authors institution and sharing with colleagues.

Other uses, including reproduction and distribution, or selling or licensing copies, or posting to personal, institutional or third party websites are prohibited.

In most cases authors are permitted to post their version of the article (e.g. in Word or Tex form) to their personal website or institutional repository. Authors requiring further information regarding Elsevier's archiving and manuscript policies are encouraged to visit:

http://www.elsevier.com/copyright 


\title{
Are there population differences in minutiae frequencies? A comparative study of two Argentinian population samples and one Spanish sample
}

\author{
Esperanza Gutiérrez-Redomero ${ }^{\mathrm{a}, \mathrm{d}, *}$, Noemí Rivaldería ${ }^{\mathrm{a}, \mathrm{d}}$, Concepción Alonso-Rodríguez ${ }^{\mathrm{b}, \mathrm{d}}$, \\ Luis M. Martín ${ }^{\mathrm{c}, \mathrm{d}}$, José E. Dipierri ${ }^{\mathrm{e}}$, Miguel A. Fernández-Peire ${ }^{\mathrm{f}, \mathrm{d}}$, Ricardo Morillo ${ }^{\mathrm{f}, \mathrm{d}}$ \\ a Departamento de Zoología y Antropología Física, Facultad de Biología, Universidad de Alcalá, Alcalá de Henares, Spain \\ ${ }^{\mathrm{b}}$ Departamento de Matemáticas, Facultad de Biología, Universidad de Alcalá, Alcalá de Henares, Spain \\ ${ }^{\mathrm{c}}$ Brigada de Policía Científica de la Comisaría de Alcalá de Henares, Spain \\ ${ }^{\mathrm{d}}$ Instituto Universitario de Investigación en Ciencias Policiales, Universidad de Alcalá, Alcalá de Henares, Spain \\ e Instituto de Biología de la Altura, Universidad Nacional de Jujuy, Argentina \\ ${ }^{\mathrm{f}}$ Comisaría General de Policía Científica, Madrid, Spain
}

\section{A R T I C L E I N F O}

\section{Article history:}

Received 26 August 2011

Received in revised form 9 June 2012

Accepted 4 July 2012

Available online 25 July 2012

\section{Keywords:}

Fingerprints

Minutiae

Frequencies

Identification

Argentina population

Spanish population

\begin{abstract}
A B S T R A C T
In recent years, both scientific and judicial sources have highlighted the need for more knowledge about minutiae variability, in order to improve their statistical application to fingerprint identification. In line with this trend toward improving our knowledge of this subject, the aim of the present study was to calculate the frequency with which 20 types of minutiae appeared in 2780 fingerprint impressions obtained from 278 individuals from two Argentinian population samples (100 individuals from Ramal and 178 from Puna-Quebrada). The different types of minutiae were located, identified, and quantified visually in two areas on the fingerprint, the inside and outside of a circle, the radius of which cut fifteen ridges perpendicularly, starting from the center cut of the axes defining the sectors. The nonequiprobability found in both population samples for the different minutiae types studied demonstrated that the evidential weight provided by these characteristics is not the same when applied in identification processes, whether used quantitatively (numerical standard) or qualitatively (holistic method). The results obtained for both populations were compared statistically with those published previously for a Spanish population sample, which had been collected using the same methodology. This comparison has enabled us to demonstrate, for the first time, the existence of significant differences between populations in minutiae frequencies, independently from the main pattern type.
\end{abstract}

(c) 2012 Elsevier Ireland Ltd. All rights reserved.

\section{Introduction}

The skin on the inner hands and fingers and on the soles of the feet and toes is characterized by alternating strips of raised ridges and furrows arranged in a variety of patterns and is called friction skin. The friction skin is the outer layer of skin that contains many of the elements and characteristics we use to identify and individualize a print. Fingerprints are the impression or reproduction left on any material by the friction skin of the fingers, and the scientific study of fingerprints for the purpose of identification is known as Dactyloscopy [1-3].

The formation of epidermal ridges occurs very early on in prenatal development $[4,5]$. Dermal papillae ridges are polygenic

* Corresponding author at: Departamento de Zoología y Antropología Física, Universidad de Alcalá, Campus Universitario, Crta. Madrid-Barcelona Km 33,6, E 28871, Alcalá de Henares (Madrid), Spain. Tel. : +34 918855074 fax: +34918855080.

E-mail address: esperanza.gutierrez@uah.es (E. Gutiérrez-Redomero). characteristics with environmental effects limited to the first few months of embryonic life [6]. Once formed, and in the absence of lesions, these ridges will remain essentially unchanged throughout the life of the individual. The exception is that, like other parts of the anatomy, the fingerprints or friction skin increase in size as the body grows [7]. Studies of their variability in human populations have demonstrated the usefulness of the information obtained about these characteristics for understanding the evolution and genetic structure of human populations [8,9], for characterizing syndromes and diseases [10-12], and for personal identification in the field of Forensic Science [13-15].

One of the basic procedures in the identification process using fingerprint impressions is a comparison of the minutiae found in fingermarks obtained at the scene of the crime with those observed in the fingerprints taken from the suspect. The problem is that the minutiae, a term coined by Galton [16] to refer to the small distinguishing features found along each individual ridge, present an inter- and intra-populational variability which has been poorly studied, despite constituting the basis for identification from fingerprint impressions in the field of Criminalistics, see $[17,18]$. 
Recent challenges to fingerprint evidence in court have strengthened the need for statistical research to underpin the fingerprint identification process. The problem of the uniqueness of fingerprint impressions was earlier addressed [16], and since then, various models have been proposed for establishing this unique identity, a critical analysis of the models proposed has been made by Stoney and Thornton [19], Stoney [20] and Srihari and Srinivasan [21]. These models have been based on very heterogeneous, and generally very small, samples and very disparate approaches (studying different types of minutiae, different fingerprint patterns, different fingers and different finger areas) see [17,18]. Recently, Neumann et al. [22-24] and Egli et al. [25] reported on the use of likelihood ratios as a means of objectively assessing the evidential weight of corresponding minutiae between a fingermark and a fingerprint.

The growing rigor with which forensic evidence is examined in the legislative area has resulted in the need to reconsider some of the basic principles that support forensic disciplines in their recognition as sciences [26-38]. In the field of fingerprints, it is necessary to study and analyze the scientific principles that determine the process of individualization in human identification. Any attempt to establish such premises must be based on increasing knowledge about of minutiae variability, given that these are one of the cornerstones of fingerprint identification, whether used quantitatively (numerical standard) or qualitatively (holistic approach) [2,18,35-39]. Linked to this issue, the National Academy of Sciences (NAS) published a report of great international impact entitled "Strengthening Forensic Science in the United States. A path forward", [35] which cited a study carried out with a Spanish population as being one of the few statistical studies of populations which have been conducted in this field in recent years [17], and emphasized the need to improve knowledge about variability in fingerprint characteristics.

In the study conducted on a sample of Spanish population $[17,38]$ the different types of minutiae were located, identified, and quantified visually on the fingerprint, following a new method of standardization, and these showed significant differences between intrafingers (topological), interfingers, and gender, which give each of the types of minutiae a different discriminatory value in the process of identification. The aim of this research was to conduct a more in-depth study on minutiae variability in other populations following the methodology used previously, thus enabling a comparison of the results.

\section{Materials and methods}

Under the aegis of a project funded by the Spanish Agency for International Cooperation (AECI) for the study and characterization of the Argentinian population, samples were collected from different populations in the northwesternmost region of the country. Presenting great geographical heterogeneity, this region can be divided into four clearly defined ecological units, regarding to the elevation or altitude in meters above sea level (m.a.s.l.): Puna (3500 m.a.s.l.), Quebrada (2500 m.a.s.l.), Valle (1200 m.a.s.l.) and Ramal (500 m.a.s.l.), which have been settled by different populations with a common genetic and cultural origin $[40,41]$. Fingerprint impressions from all ten fingers were collected from a sample of adult individuals of both sexes in three of the regions mentioned above: Puna and Quebrada (>2500 m.a.s.l.) and Ramal (500 m.a.s.l.).

The samples were collected at the Police Academy at San Salvador de Jujuy and at various educational institutions in the province, with the informed consent of the individuals studied. Samples were collected from a total of 278 adult individuals. Of these, 100 (51 males and 49 females) were from the city of San Pedro de Jujuy, located in the Ramal region, and 178 ( 85 males and
93 females) were from different locations in the regions of Puna and Quebrada. Total sample size, therefore, was 2780 fingerprint impressions. Subject occupation was taken into account, and those who were employed in manual work were excluded from the study as this could affect the morphological analysis of dermal papillae ridges.

The technique used to collect fingerprint impressions was a variation on the adhesive paper and graphite method described by Aase and Lyons [42]. Fingertip papillae ridges were stained homogeneously with graphite powder and then rolled over the sticky side of an appropriately sized label. Next, these labels were stuck to transparent acetate sheets which had been designed so that each sheet had ten separate areas for depositing each of the ten fingerprint impressions obtained from a single individual. The fingers were assigned the numbers 1-10, starting from the right thumb, or finger 1 (F1), and ending with the left little finger, or finger 10 (F10). The image of the fingerprint impression thus obtained provides a mirror image of the fingerprint, similar to that achieved using the classical ink and paper technique. The fingerprints were digitalized, finger by finger, on the premises of the Commissary of Scientific Police at Alcalá de Henares (Madrid). Each true color (24bit) jpg image had a size of $1496 \times 2002$ pixels, with a resolution of $200 \mathrm{ppi}$ or 79 pixels $/ \mathrm{cm}$.

Identification of the minutiae in this study was based on a modified version, see $[17,38]$, of the classification system used by the Spanish Scientific Police [43]. A total of 20 types of minutiae were identified and quantified visually on the inside and the outside of a circle, the radius of which cuts fifteen ridges perpendicularly, in one of the distal quadrants, starting from the center cut of the two perpendicular axes located at the center of the fingerprint (Fig. 1). The standardization chosen for this study has been done with the aim of comparing the central and peripheral areas of the fingerprint in all pattern types (arches, radial loops, ulnar loops, and whorls). Therefore, the standardization has been made, seeking a distribution of areas, similar in size, so that the designed circle remains located in the central area of the finger (which is picked up more frequently in fingermarks). This allows us to assess the complete topological distribution of the minutiae on the fingerprint's surface and to create results comparable across populations (Spanish and Argentinian). The circle is used to eliminate, as far as possible, the effect of finger size. Thus, this standardization allows comparison of minutiae frequencies between different fingers, genders and populations.

This facilitated the individualization of 5560 ridge count areas for analysis; i.e., 2 areas (outside and inside circle) on 2780 fingerprints (Fig. 1), on which 233,251 minutiae were found. Coding of the fingerprints allowed us to build a database consisting of 278 individuals and 412 variables by individual (number of minutiae counted in 2 areas $\times 10$ fingers $\times 20$ types of minutiae, sex, place of birth and general pattern type for each of the 10 fingers).

The sample was statistically analyzed using SPSS 15.0 and Statistica 7 software. For both populations, minutiae frequencies over the total area of the impression and inside/outside the circle were calculated for the total sample and by sex. We used the test for independence of characteristics (Chi-square) to study the data. When dependence was detected, we applied a simple correspondence analysis to explain where this dependence was located in a two-way contingency table; i.e., a frequency table with only two categorical variables. A summarized description of this method can be seen in Gutiérrez-Redomero et al. [38]. We analyzed the relationship between both of the main patterns (UL-ulnar loop and $\mathrm{W}$-whorl) and minutiae type frequency. We used the test for difference between proportions to evaluate minutiae frequencies and the main patterns, together with correspondence analysis. 


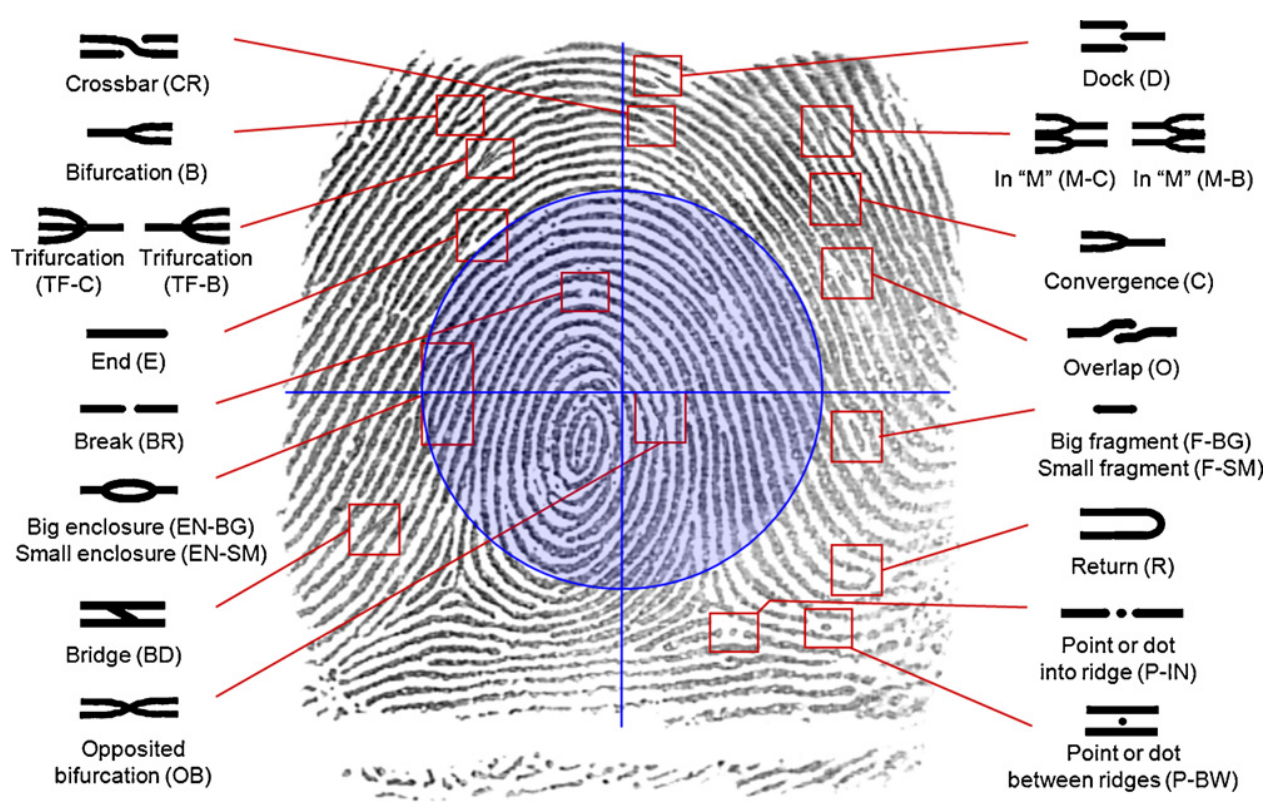

Fig. 1. Idealization of 20 types of minutiae used in this study and ridge count areas (inside and outside the circle).

The results obtained from this study of Argentinian samples were compared with those of a Spanish population sample, collected and analyzed in a previous study [38] using the same methodology. To compare the data obtained for the three populations, we used the test for difference between proportions and the test for independence of characteristics (Chi-square), conducting a correspondence analysis whenever dependence was detected. Furthermore, the interpopulation comparison of the minutiae frequencies has been conditioned by general pattern (arch, loop, and whorl).

\section{Results}

The minutiae frequencies, for the total sample and by sex, obtained from 1000 fingerprint impressions from the Ramal sample and 1780 from the Puna-Quebrada sample are shown in Tables 1 and 2, respectively. For the total sample (males and females), and for both populations, we observed that the frequency of endings ( $\mathrm{E}$ ) was considerably higher than the rest of the minutiae (Ramal: 50.14\%; Puna-Quebrada: 51.69\%), followed by the frequency of bifurcations (B) (Ramal: 21.17\%, Puna-Quebrada: 19.91\%) and convergences (C) (Ramal: 19.19\%, Puna-Quebrada: $18.28 \%$ ). The rest of the minutiae presented considerably lower frequencies. In the Ramal sample (Table 1 ), fragments (F), whether large (F-BG) or small (F-SM), crossbars (CR) and bridges (BD) presented frequencies which ranged from $1 \%$ to $2 \%$; whilst in the Puna-Quebrada sample (Table 2), fragments (F), whether large (F$\mathrm{BG}$ ) or small (F-SM), breaks (BR) and points between ridges (P-BW) were the characteristics which presented frequencies between $1 \%$ and $2 \%$. The remaining minutiae analyzed presented frequencies of less than $1 \%$. The distribution of minutiae frequencies in both populations highlighted their non-equiprobability $(p<0.01)$. Inside the circle, both populations presented lower frequencies for endings (E) than they presented outside the circle. In contrast,

Table 1

Frequencies registered for minutiae from the Ramal sample, totals, males and females, inside and outside the circle and total area (of the ten fingers), $n=$ total number of minutiae, ${ }^{\mathrm{a},}{ }^{\mathrm{b}} \mathrm{p}<0.05$

\begin{tabular}{|c|c|c|c|c|c|c|c|c|c|}
\hline & \multicolumn{3}{|c|}{ Total $(n=85,269)$} & \multicolumn{3}{|c|}{ Males $(n=44,923)$} & \multicolumn{3}{|c|}{ Females $(n=40,346)$} \\
\hline & Total area & Inside circle & Outside circle & Total area & Inside circle & Outside circle & Total area & Inside circle & Outside circle \\
\hline $\mathrm{E}$ & 50.139 & 45.495 & 53.168 & 49.638 & 45.045 & $52.511^{\mathrm{a}}$ & 50.696 & 45.970 & $53.926^{\mathrm{a}}$ \\
\hline B & 21.166 & 24.015 & 19.308 & 21.848 & $24.967^{\mathrm{b}}$ & 19.898 & 20.406 & $23.009^{\mathrm{b}}$ & 18.627 \\
\hline C & 19.188 & 20.221 & 18.513 & 19.841 & 20.836 & 19.218 & 18.460 & 19.571 & 17.701 \\
\hline F-BG & 1.093 & 1.043 & 1.126 & 0.966 & 0.879 & 1.020 & 1.234 & 1.215 & 1.247 \\
\hline $\mathrm{F}-\mathrm{SM}$ & 1.495 & 1.420 & 1.544 & 1.269 & 1.221 & 1.299 & 1.747 & 1.630 & 1.827 \\
\hline BR & 0.814 & 0.838 & 0.798 & 0.759 & 0.821 & 0.720 & 0.875 & 0.855 & 0.889 \\
\hline EN-BG & 0.911 & 1.245 & 0.694 & 0.850 & 1.192 & 0.637 & 0.979 & 1.301 & 0.759 \\
\hline EN-SM & 0.774 & 1.153 & 0.527 & 0.748 & 1.145 & 0.499 & 0.803 & 1.160 & 0.559 \\
\hline P-BW & 0.493 & 0.556 & 0.452 & 0.414 & 0.486 & 0.369 & 0.580 & 0.629 & 0.547 \\
\hline P-IN & 0.063 & 0.059 & 0.066 & 0.049 & 0.075 & 0.033 & 0.079 & 0.043 & 0.104 \\
\hline 0 & 0.751 & 0.654 & 0.814 & 0.735 & 0.619 & 0.807 & 0.768 & 0.690 & 0.822 \\
\hline CR & 1.328 & 0.891 & 1.612 & 1.701 & 1.041 & 2.113 & 0.912 & 0.733 & 1.035 \\
\hline BD & 1.230 & 1.673 & 0.942 & 0.761 & 1.093 & 0.554 & 1.752 & 2.284 & 1.389 \\
\hline $\mathrm{OB}$ & 0.224 & 0.258 & 0.202 & 0.127 & 0.150 & 0.112 & 0.332 & 0.372 & 0.305 \\
\hline D & 0.054 & 0.056 & 0.052 & 0.038 & 0.040 & 0.036 & 0.072 & 0.073 & 0.071 \\
\hline TF-B & 0.056 & 0.107 & 0.023 & 0.047 & 0.098 & 0.014 & 0.067 & 0.116 & 0.033 \\
\hline TF-C & 0.024 & 0.045 & 0.010 & 0.013 & 0.035 & 0.000 & 0.035 & 0.055 & 0.021 \\
\hline M-B & 0.101 & 0.128 & 0.083 & 0.093 & 0.110 & 0.083 & 0.109 & 0.147 & 0.083 \\
\hline M-C & 0.097 & 0.146 & 0.066 & 0.102 & 0.145 & 0.076 & 0.092 & 0.147 & 0.054 \\
\hline
\end{tabular}


Table 2

Frequencies registered for minutiae from Puna-Quebrada sample, totals, males and females, inside and outside the circle and total area (of the ten fingers), $n=$ total number of minutiae found in area, ${ }^{\text {a }, ~ b, ~}{ }^{c} p<0.05$.

\begin{tabular}{|c|c|c|c|c|c|c|c|c|c|}
\hline & \multicolumn{3}{|c|}{ Total $(n=147,982)$} & \multicolumn{3}{|c|}{ Males $(n=72,073)$} & \multicolumn{3}{|c|}{ Females $(n=75,909)$} \\
\hline & Total area & Inside circle & Outside circle & Total area & Inside circle & Outside circle & Total area & Inside circle & Outside circle \\
\hline $\mathrm{E}$ & 51.690 & 45.458 & 55.756 & 53.469 & $46.676^{\mathrm{a}}$ & $57.626^{\mathrm{b}}$ & 50.001 & $44.387^{\mathrm{a}}$ & $53.890^{\mathrm{b}}$ \\
\hline B & 19.906 & 22.806 & 18.014 & 19.161 & 22.271 & $17.259^{c}$ & 20.613 & 23.278 & $18.766^{\mathrm{c}}$ \\
\hline C & 18.278 & 21.033 & 16.480 & 16.977 & $20.169^{\mathrm{a}}$ & $15.024^{\mathrm{b}}$ & 19.513 & $21.794^{\mathrm{a}}$ & $17.932^{\mathrm{b}}$ \\
\hline F-BG & 1.415 & 1.354 & 1.455 & 1.469 & 1.276 & 1.588 & 1.363 & 1.423 & 1.322 \\
\hline F-SM & 2.284 & 2.198 & 2.340 & 2.356 & 2.230 & 2.433 & 2.216 & 2.169 & 2.248 \\
\hline BR & 1.122 & 1.145 & 1.108 & 1.224 & 1.385 & 1.125 & 1.026 & 0.933 & 1.091 \\
\hline EN-BG & 0.758 & 1.030 & 0.580 & 0.795 & 1.118 & 0.597 & 0.722 & 0.953 & 0.562 \\
\hline EN-SM & 0.988 & 1.427 & 0.701 & 0.814 & 1.203 & 0.577 & 1.153 & 1.625 & 0.825 \\
\hline P-BW & 1.039 & 1.195 & 0.937 & 1.371 & 1.521 & 1.279 & 0.723 & 0.908 & 0.595 \\
\hline P-IN & 0.099 & 0.087 & 0.107 & 0.121 & 0.113 & 0.125 & 0.079 & 0.064 & 0.089 \\
\hline 0 & 0.793 & 0.649 & 0.888 & 0.795 & 0.654 & 0.881 & 0.792 & 0.644 & 0.894 \\
\hline CR & 0.809 & 0.556 & 0.974 & 0.688 & 0.450 & 0.834 & 0.923 & 0.650 & 1.113 \\
\hline $\mathrm{BD}$ & 0.576 & 0.779 & 0.444 & 0.513 & 0.691 & 0.405 & 0.636 & 0.856 & 0.484 \\
\hline OB & 0.080 & 0.096 & 0.069 & 0.082 & 0.099 & 0.072 & 0.078 & 0.093 & 0.067 \\
\hline $\mathrm{D}$ & 0.076 & 0.050 & 0.093 & 0.097 & 0.058 & 0.121 & 0.055 & 0.042 & 0.065 \\
\hline TF-B & 0.020 & 0.034 & 0.010 & 0.014 & 0.022 & 0.009 & 0.025 & 0.045 & 0.011 \\
\hline TF-C & 0.014 & 0.027 & 0.006 & 0.010 & 0.018 & 0.004 & 0.018 & 0.035 & 0.007 \\
\hline M-B & 0.032 & 0.034 & 0.030 & 0.029 & 0.022 & 0.034 & 0.034 & 0.045 & 0.027 \\
\hline M-C & 0.020 & 0.036 & 0.009 & 0.011 & 0.018 & 0.007 & 0.028 & 0.051 & 0.011 \\
\hline $\mathrm{R}$ & 0.002 & 0.005 & 0.000 & 0.003 & 0.007 & 0.000 & 0.001 & 0.003 & 0.000 \\
\hline
\end{tabular}

bifurcations (B) and convergences (C) were more frequent inside the circle. These differences were statistically significant in all cases (Tables 1 and 2).

In the Ramal sample, a comparison between the sexes showed that males presented significantly more bifurcations (B) inside the circle and fewer endings (E) outside it than females (Table 1 ). Convergences (C) were more frequent in the males than the females, both inside and outside the circle. In the Puna-Quebrada sample (Table 2 ), we found that the males presented significantly more endings (E) and fewer convergences (C) than the females, both inside and outside the circle. Significant differences for bifurcations (B) were only found outside the circle, and these were less frequent in the males.

The distribution of the different types of minutiae was significantly dependent on finger area (inside and outside the circle) and sex. The correspondence analysis for both populations is shown in Fig. 2. In the Ramal sample, both dimensions explained 97.07\% (Fig. 2a) and in the Puna-Quebrada sample, $98.02 \%$
(Fig. 2b). For both populations, the first dimension separated the distribution of minutiae frequencies in the periphery of the dactylogram (outside the circle) from those in the central area (inside the circle), and it was this latter area which presented the greatest diversity of minutiae types. The second dimension separated females from males, with the former presenting a greater diversity of minutiae types.

We explored the relationship between the distribution of minutiae types and the fingers (F1,.., F10), considering total finger surface area and inside and outside the circle, for both populations, and found significant dependence in all areas. The correspondence analysis demonstrating this dependence inside the circle in both populations is shown in Fig. 3. In the Ramal sample (Fig. 3a), the two dimensions explained $91.12 \%$ of inertia. The first dimension separated the right hand fingers from those of the left hand, and the second dimension separated the thumb fingers (F1 and F6) from the rest of the fingers. Endings (E) were located very close to the coordinate center and were, by far, the most frequent type of
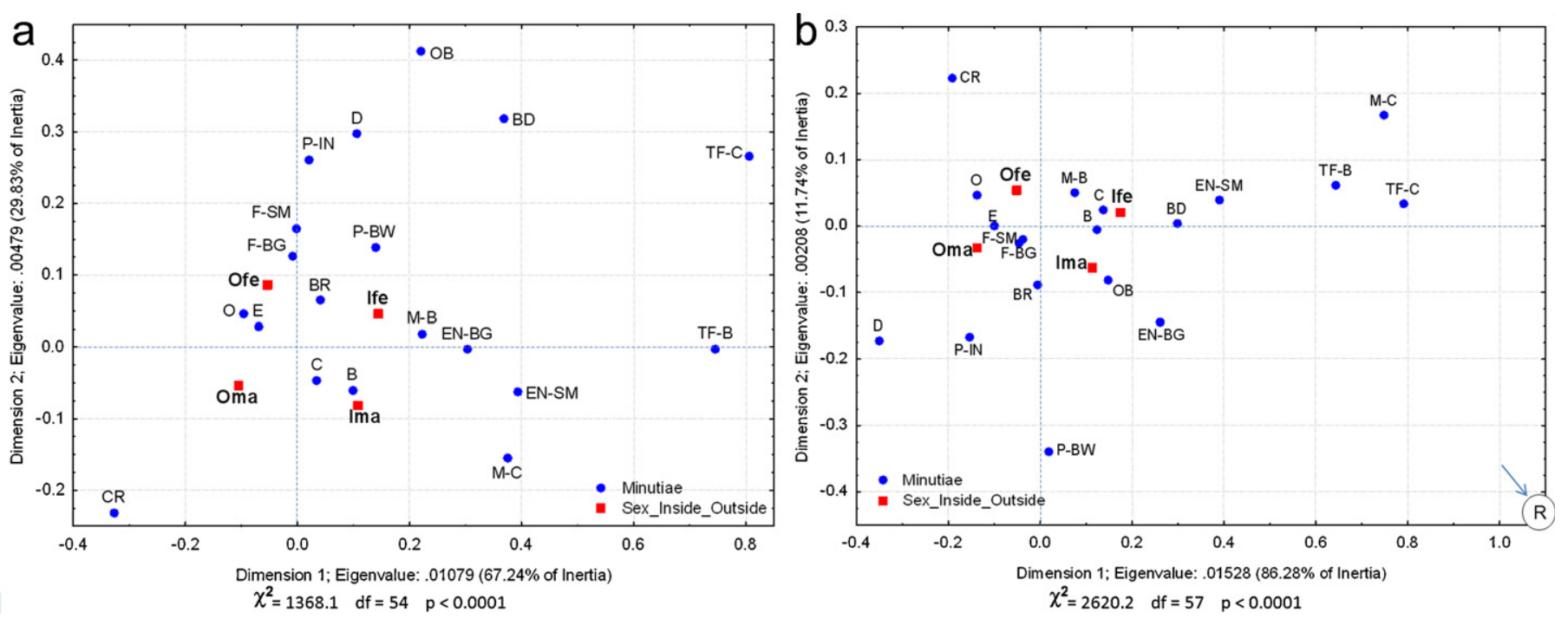

Fig. 2. Analysis of correspondence between the types of minutiae, genders (males: ma and females: fe) and areas (inside circle: I and outside circle: O): (a) Ramal sample; (b) Puna-Quebrada sample (the minutiae R, far away from all others, have been cut from the graph and placed on the periphery - lower right corner - for a better visualization of the relationships among of the other minutiae). 

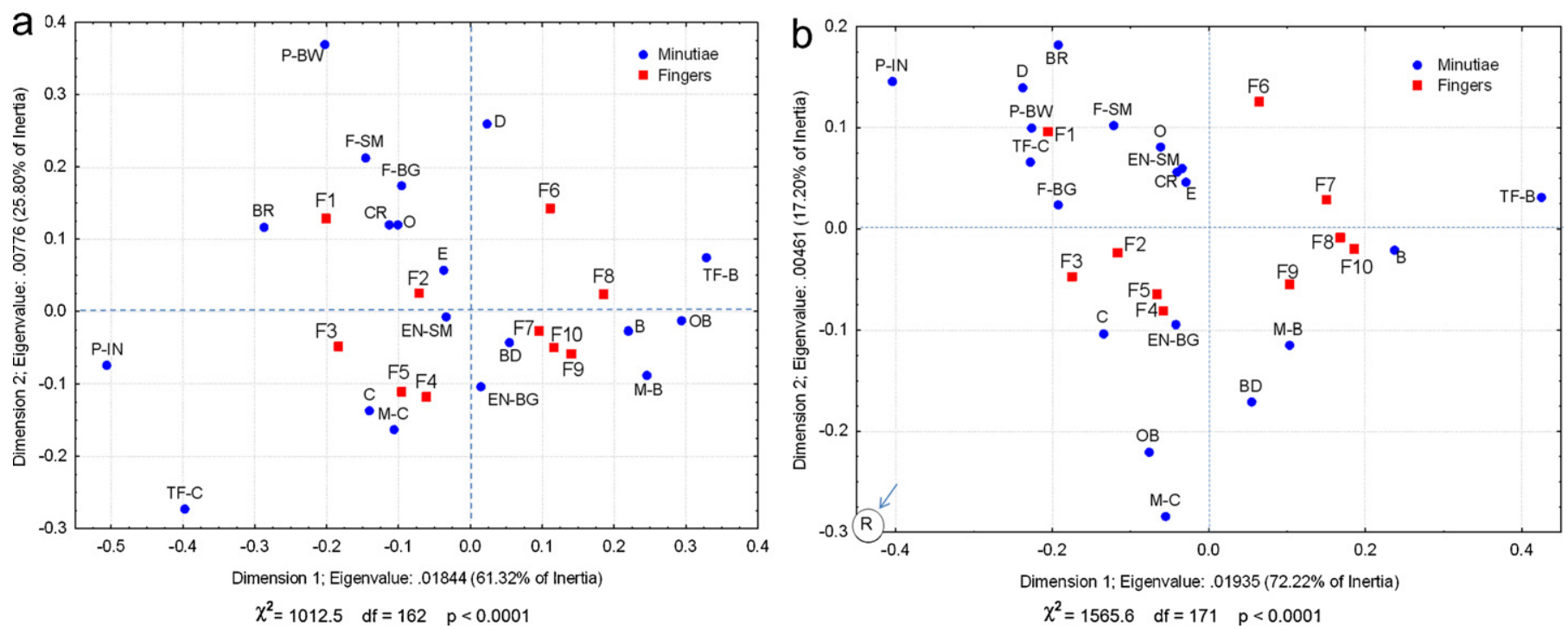

Fig. 3. Analysis of correspondence between the types of minutiae and the ten fingers (F1,.., F10) in the central area of the fingerprint (inside circle): (a) Ramal sample; (b) Puna-Quebrada sample (the minutiae R, far away from all others, have been cut from the graph and placed on the periphery - lower left corner - for a better visualization of the relationships among of the other minutiae).

minutiae in all fingers. Convergences (C) were associated with the middle (F3), ring (F4) and little (F5) fingers of the right hand. In contrast, bifurcations (B) were more associated with the left hand, and in particular, with the index (F7), middle (F8), ring (F9) and little (F10) fingers. The remaining minutiae were largely associated with the thumbs (F1 and F6) and index fingers (F2 and F7). All convergent minutiae ( $\mathrm{C}, \mathrm{TF}-\mathrm{C}, \mathrm{M}-\mathrm{C})$, or negative direction (sensu Champod, [44]), were more frequent on the right hand; in contrast, it was the bifurcate minutiae (B, TF-B, M-B), or positive direction (sensu Champod, [44]), that were most frequent on the left hand. In the Puna-Quebrada sample (Fig. 3b), the two dimensions significantly explained $89.42 \%$ of inertia, and the first dimension separated the right hand fingers from those of the left hand, whilst the second dimension separated the thumbs of both hands (F1 and F6) and the left hand index finger (F7) from the rest of the fingers. In the Ramal sample, the association between fingers and
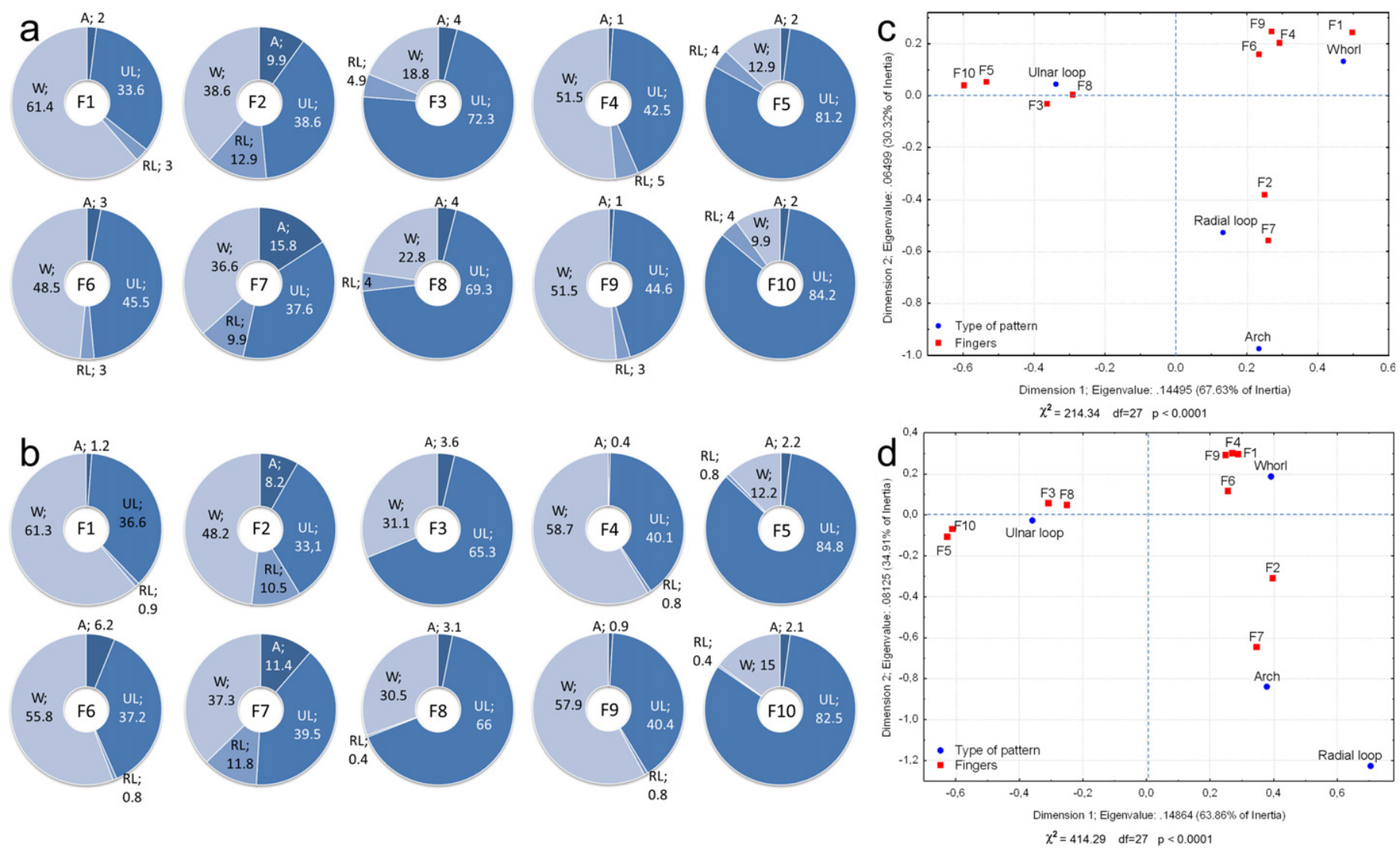

Fig. 4. Frequencies for the type of patterns by finger (F1,.., F10): (a) Ramal sample; (b) Puna-Quebrada sample. Analysis of correspondence between general patterns and the fingers: (c) Ramal sample; and (d) Puna-Quebrada sample. 

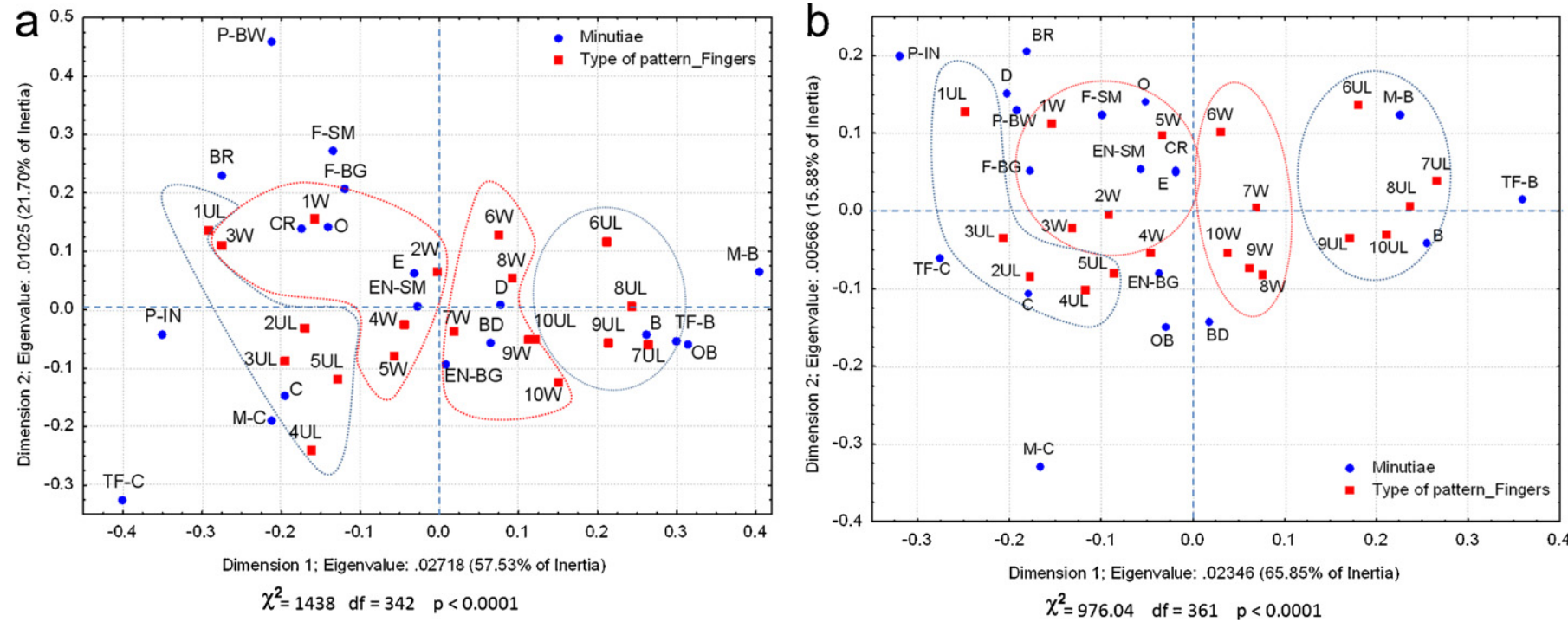

Fig. 5. Analysis of correspondence between the types of minutiae and the two most frequent types of patterns: ulnar loop (UL) and whorl (W), for each finger (1,.., 10): (a) Ramal sample; (b) Puna-Quebrada sample.

bifurcations and convergences presented the same pattern. In addition, it can be seen that the thumbs separated from the other fingers. This pattern of association also appeared outside the circle, in both populations. Similarly, when the total sample (both populations) was analyzed by sex, we found that both males and females presented the same type of association and dependence between the distribution of minutiae types and fingers.

The frequency found for main pattern types by finger, for both Argentinian samples, is shown in Fig. 4. These did not present significant differences between samples or between sexes. In Fig. 4a-b, similar values between homologue fingers can be seen in both populations: whorls were more frequent on thumbs and ring fingers (F1, F4, F6 and F9), whilst ulnar loops were more frequent on the middle and little fingers (F3, F5, F8 and F10). The index fingers of both hands (F2 and F7) presented a higher frequency of arches and radial loops, with similar frequencies for whorls and ulnar loops. Correspondence analysis between main pattern type and fingers revealed a significant association between them (Fig. 4c-d): in both populations, the thumbs (F1 and F6) and ring fingers (F4 and F9) were associated with whorls, the middle (F3 and F8) and little (F5 and F10) fingers with ulnar loops, and the index fingers (F2 and F7) with arches and radial loops. In the Ramal sample, the two dimensions explained $97.95 \%$ of the variability found, whilst in the Puna-Quebrada sample, they explained 98.77\%. In both samples, the first dimension separated the middle (F3 and F8) and little (F5 and F10) fingers, which presented more ulnar loops, from the rest of the fingers, which had more whorls.

The dependence between the minutiae and the main pattern types, by fingers (F1,.., F10), was statistically significant in both populations (Fig. 5). For the sample inside the circle, Fig. 5 shows the CA between the types of minutiae and the two most frequent types of patterns, ulnar loops (UL) and whorls (W) for each finger. The return minutia $(\mathrm{R})$ is an outlier, i.e. far away from all others and from the point of origin, and therefore this minutia indicates a clear

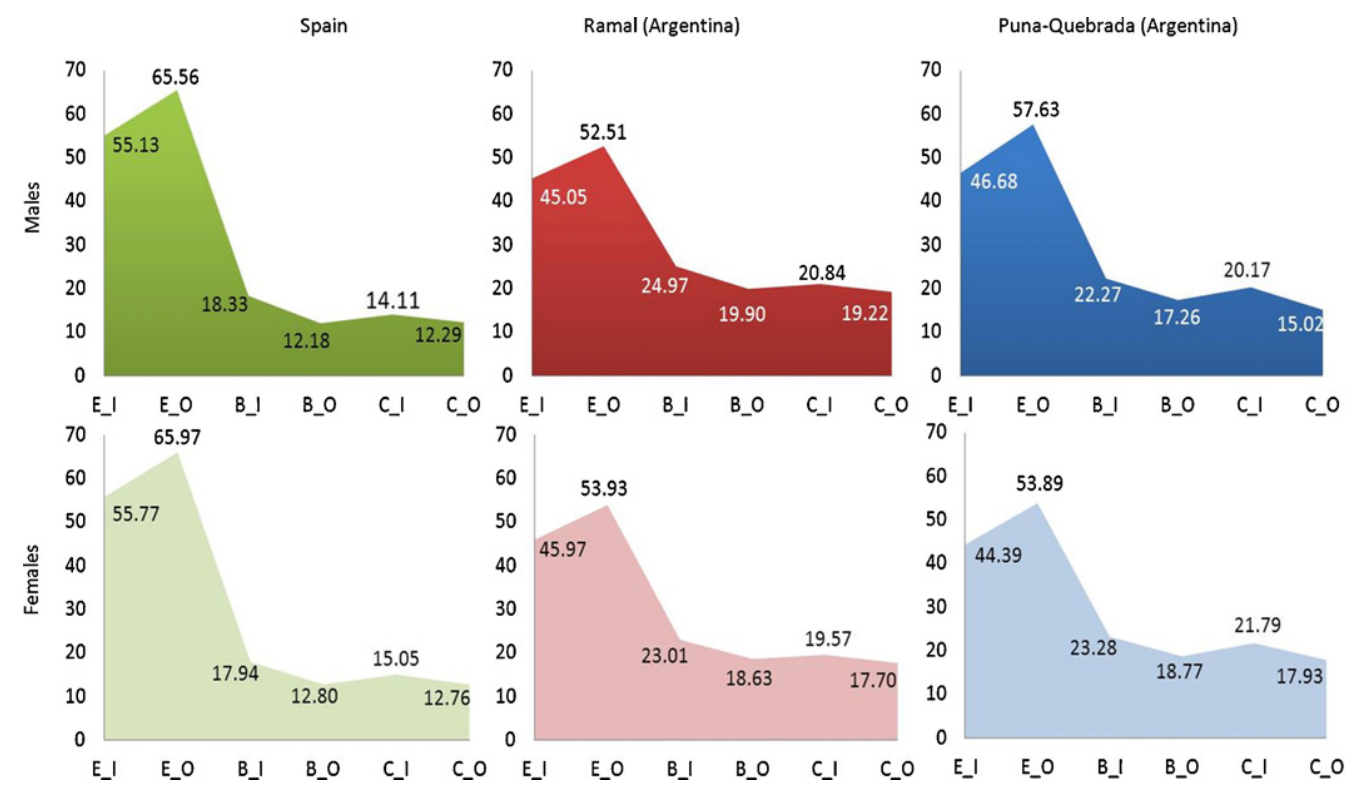

Fig. 6. Frequency of endings (E), bifurcations (B) and convergences (C), considering both inside and outside the circle, for the Argentinian populations (Ramal and PunaQuebrada) and the Spanish population samples [82]. 

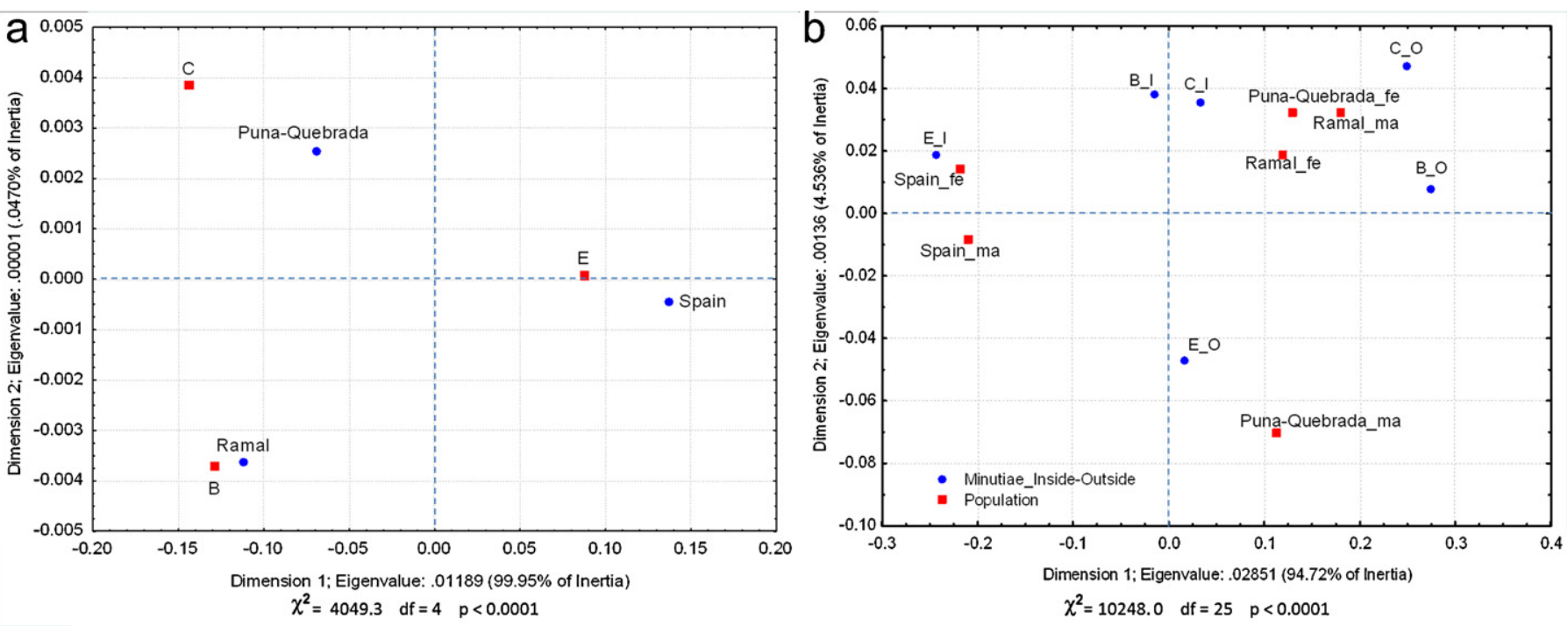

Fig. 7. (a) Analysis of correspondence between the types of minutiae (endings - E, bifurcations - B and convergences - C), and Argentinian populations (Ramal and PunaQuebrada) and the Spanish population samples. (b) Analysis of correspondence between the types of minutiae (endings - E, bifurcations - B and convergences - C), genders (males: ma and females: fe) and areas (inside circle: I and outside circle: O) for Argentinian populations (Ramal and Puna-Quebrada) and the Spanish population samples.

deviation from what we would expect under complete independence. It has been cut from the graph and placed on the periphery, to provide a better visualization of the relationships between the other minutiae in the Puna-Quebrada sample (Fig. 5b). For the Ramal sample, correspondence analysis explained $79.23 \%$ of inertia (Fig. 5a), and $81.73 \%$ for the Puna-Quebrada sample (Fig. 5b). The first dimension separated the right hand fingers from those of the left hand, in both populations. Fingers with ulnar loops as the main pattern type were greater determinants of dependence between minutiae types and fingers, and their distribution in the analysis was thus found to be further from the center of gravity. Meanwhile, the second dimension separated the thumbs of both hands, whether with whorls or ulnar loops, from the rest of the fingers, which were more associated with convergences (C) on the right hand (F2, ..., F5) and bifurcations (B) on the left hand (F7, ..., F10). In the analysis, endings (E) were located close to the coordinate axis, or center of gravity, contributing less to dependence since they were the most frequent type minutiae of in both samples (Fig. 5).

A comparison is shown in Fig. 6 of the frequency results for the Argentinian populations and the Spanish population sample published previously [38], considering endings (E), bifurcations (B) and convergences (C), both inside and outside the circle. The differences observed in these three types of minutiae (endings-E, bifurcations-B and convergences- $C$ ) between the Spanish sample and the Ramal and Puna-Quebrada samples were statistically significant both inside and outside the circle and for both sexes: endings (E) were more frequent in the Spanish sample, whilst bifurcations (B) and convergences (C) were more frequent in the Argentinian samples. Puna-Quebrada males presented significantly more endings (E) and fewer bifurcations (B) than Ramal males, both inside and outside the circle. In addition, the Puna-Quebrada males presented fewer convergences (C) outside the circle than the Ramal males. In contrast, both inside and outside the circle the Puna-Quebrada females presented significantly lower frequencies of endings (E) and more bifurcations (B) than the Ramal females. In addition, the Puna-Quebrada females presented significantly more convergences $(\mathrm{C})$ inside the circle than the Ramal females (Fig. 6).

The relationship between ending (E), bifurcation (B) and convergence (C) frequencies and the three samples (Two Argentinian population samples from Ramal and Puna-Quebrada and a Spanish population sample) was statistically dependent.
Consequently, we conducted a correspondence analysis, shown in Fig. 7. In Fig. 7a, the two dimensions explained 99.99\% of inertia, with the first dimension separating the Spanish population, who presented a higher frequency of endings (E), from the Argentinian populations (Ramal and Puna-Quebrada), who presented lower frequencies of bifurcations (B) in the Ramal sample, and of convergences $(C)$ in the Puna-Quebrada sample. Fig. 7b shows the results of the correspondence analysis considering sex. In this analysis, the two dimensions explained $99.26 \%$ of inertia. The first dimension separated both sexes of the Spanish population from the Argentinian population, whilst the second dimension separated all females and the Ramal males from the Puna-Quebrada and Spanish males.

As the influence of pattern type on the number of minutiae is shown by an increase from arches (no delta) to loops (one delta) to whorls (two or more deltas and complexity of the center) the impact of general pattern on interpopulation variation was investigated. Fig. 8 shows that pattern frequencies are quite different between the Argentinian and Spanish populations. Moreover, the dependence on the main pattern types by population was statistically significant in both populations, with chi-square $=95.06$ and $p<0.0001$. There are lower frequencies of ulnar loops and whorls, but higher frequencies of arches and radial loops in the Spanish populations than in the Argentinian populations.

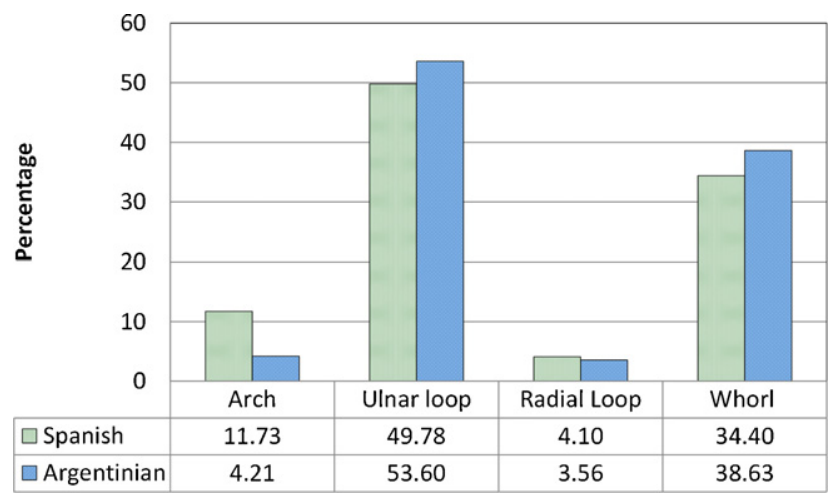

Fig. 8. Frequencies for the pattern type by population: Spanish and Argentinian (Ramal and Puna-Quebrada together). 

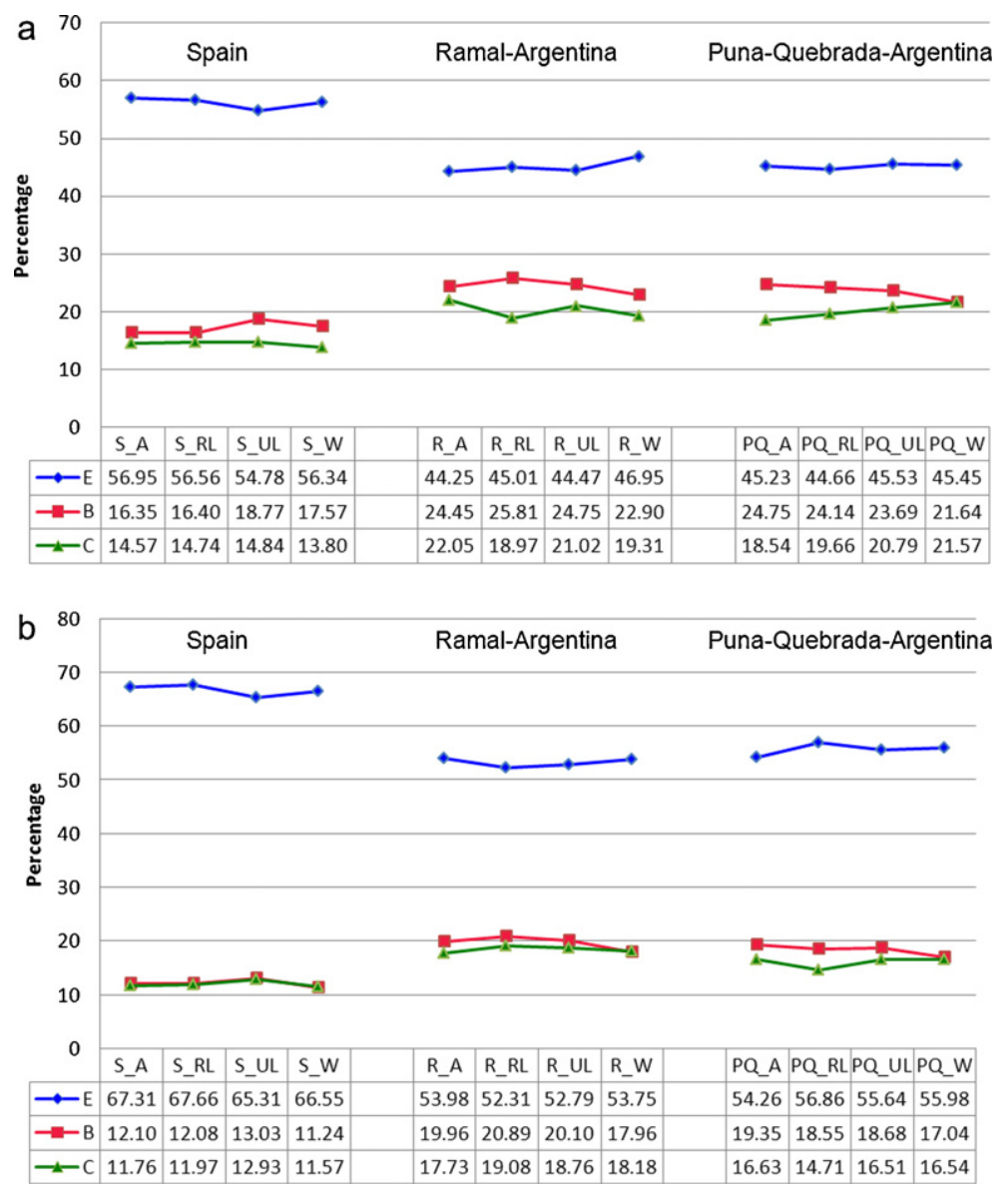

Fig. 9. Frequency of endings (E), bifurcations (B), and convergences (C) of the ten fingers for the Spanish (S) [38] and Argentinian [Ramal (R) and Puna-Quebrada (PQ)] population samples when conditioning by general pattern [arch (A), radial loop (RL), ulnar loop (UL), and whorl (W)], considering (a) inside and (b) outside the circle.

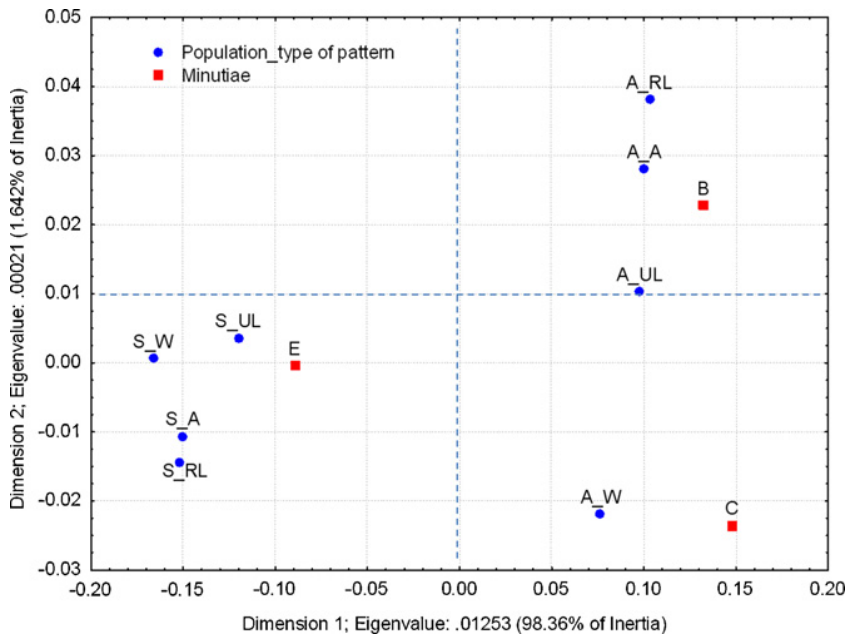

Fig. 10. Analysis of correspondence between the types of minutiae [endings (E), bifurcations (B), and convergences (C)] as well as the Argentinian (Ramal and PunaQuebrada together) and Spanish population samples for the total area (of the ten fingers) when conditioning by general pattern: arch (A), radial loop (RL), ulnar loop (UL), and whorl (W).

When conditioning using general pattern, the relationship between ending (E), bifurcation (B), and convergence (C) frequencies and the three samples (two Argentinian population samples from Ramal and Puna-Quebrada and one Spanish population sample) was statistically dependent, both inside and outside the circle, as shown in Fig. 9. The results reveal higher frequencies of endings (E) and lower frequencies of bifurcations (B) and convergences (C) for all pattern types in the Spanish population than in the Argentinian populations. The significant dependency among minutiae (E, B, and $\mathrm{C}$ ), type of pattern, and population is shown in Fig. 10. The graph obtained with correspondence analysis highlights the association of endings with the Spanish population in all pattern types (arches, radial loops, ulnar loops, and whorls) and the association of bifurcations and convergences with the Argentinian population.

\section{Discussion}

Although numerous studies have been carried out on the fingerprints of human populations, some of their inherent characteristics have received more attention than others. These include aspects such as frequency of the main pattern types (archA, radial loop-RL, ulnar loop-UL and whorl-W) and the partial (RC) or total (RCT) ridge count, as well as their variability and heredity in different human populations (see bibliography checklist in $[45,46])$. However, other features, such as the minutiae, have received comparatively less attention, despite being of considerable interest due to their direct relevance in personal identification and despite early recommendations from various specialists $[13,47-52]$.

Thus, it is difficult to compare the results obtained in the present study with those which have been published previously due to the different criteria employed, not only as regards classification of the minutiae, but also in terms of the methods employed for their assessment [47-57]. All other studies, with the exception of those conducted by Gutiérrez-Redomero et al. 
[17-38], have been based on fingerprint samples from males, and vary considerably as regards sample size (from 39 to 1000 fingerprint impressions), number of fingers selected for analysis (only the thumb, only the index and middle fingers, or other combinations), the finger areas assessed (distal tips, nuclear area, delta area, etc.) and the type of main pattern type selected (usually the ulnar loop-UL and Whorl-W). The recent classifications by Ashbaugh [3] and Champod [44], with nine main types, are the most similar to the classifications which were used in the present study. Standardization of minutiae classification criteria is a highly desirable objective in order to facilitate comparison between different human populations using a greater number of morphological minutiae characteristics. The advantage of using more minutiae types stems from the fact that the less frequent types are accordingly the most exceptional, and therefore, the most useful for identification purposes $[2,13,18,30,57]$. For all these reasons, it was only possible to conduct a very general comparison of the minutiae frequencies obtained in our study with the majority of those which have already been published. Nevertheless, this general comparison indicated that the most frequent types of minutiae are endings, followed by convergences and bifurcations, although in the majority of the samples from other studies, the latter two types of minutiae were not analyzed separately. As in our study, the rest of the minutiae have been found to present considerably lower frequencies. In contrast, it was possible to compare the data we have presented here with the findings reported by Gutiérrez-Redomero et al., $[17,38]$ for a Spanish population sample, which was collected and analyzed using the same methodology.

The results obtained in this study show, for the first time, the topological, finger and sex differences presenting in fingerprint impressions taken from two Argentinian population samples. Our results for both samples reflect the heterogeneous distribution of minutiae on the finger area, with differences in frequency between the different areas assessed. Coinciding with findings for the Spanish population [38], endings were located with more frequency outside the circle (peripheral area of the fingerprint), whilst bifurcations and convergences were more frequent inside the circle (central area of the fingerprint). Other authors, such as Kingston [48], Lin [53] and Sclove [52], have reported that minutiae density varies according to location on the fingerprint impression, and more recently, Champod and Margot [55] have confirmed these results, finding a higher density of minutiae in the nuclear and delta (triradii) areas than in the periphery of the impression. In relation to sex, and in contrast to the Spanish population [38] where no sex differences were found in minutiae type frequencies, both Argentinian populations did present differences for endings and bifurcations; the females presented a higher frequency of endings, and the males, of bifurcations.

Given the mirror image the hands present, the bifurcate minutiae assessed (B, TFB and $\mathrm{MB}$ ) were associated with the left hand, whilst the convergent minutiae (C, TFC and MC) were associated with the right hand, coinciding with findings for the Spanish population [38]. Champod and Margot [55] highlighted the association of bifurcations in a positive direction (referred to as bifurcations in this study) with ulnar loops on the left hand, and bifurcations in a negative direction (referred to as convergences in this study) with ulnar loops on the right hand. As with the Spanish population, in the present study we found that this association also holds true for whorls.

As regards main pattern type, the South American Indians have greater variation in frequency than any other American population (Eskimos, North American Indians and Central American Indians) $[58,59]$. The finger pattern type frequencies found in the two Argentinian samples fell within the distribution range described for South American populations, and as with all other Andean populations analyzed, the Puna-Quebrada sample presented a high frequency of radial loops [58,60]. The Argentinian samples were characterized by presenting more whorls and fewer ulnar loops than other Spanish population samples. The main pattern frequency distribution for each finger shows that the universally observed pattern of an association between whorls and thumbs and ring fingers, ulnar loops and middle and little fingers and arches and radial loops and index fingers [10: pp. 79] is also evident in these samples.

Although the topological distribution pattern presented by endings (E), bifurcations (B) and convergences (C) in the Argentinian and Spanish populations coincided, we found significant differences, for the first time, in the frequency of minutiae in all the areas compared (total area and outside/inside the circle). Thus, the Spanish population presented significantly higher frequencies of endings (E), and lower frequencies of bifurcations (B) and convergences (C) than either of the Argentinian populations. Given the differences observed between the two populations in terms of the frequencies of pattern types and the impact this might have on the significant differences found for the three types of minutiae (E, B and C), a comparison of conditioning by general pattern was conducted, which confirmed previous results. Therefore, the frequencies of minutiae change in relation to population, but it should change independently of the pattern type. This highlights the existence of significant differences as regards the minutiae frequencies presented by these populations. Further research is nevertheless required in order to determine the magnitude of these differences in other human populations.

In an identification process based on the comparison of morphological characteristics such as the minutiae, it is important to bear in mind the discriminatory power of these characteristics, given the different frequencies with which they appear in different populations $[15,18]$. For this reason, in a fingerprint identification, whether or not based on a numerical standard, the evidential weight of minutiae such as endings (E), with frequencies which range from $45 \%$ to $66 \%$ depending on the finger area, sex and population analyzed, cannot be the same as that of bifurcations or convergences, with frequencies which vary between $12 \%$ and $25 \%$, or the rest of the minutiae, such as points (P-BW o P-IN), crossbars $(\mathrm{CR})$, bridges $(\mathrm{BD})$ or opposited bifurcations $(\mathrm{OB})$, with frequencies which range between $3 \%$ and $0.1 \%$.

The application of mathematical models for the probabilistic calculation of identity based on fingerprint impressions would be useful in the identification process, and to have quantitative data related to different types of minutiae and their distributions could be of great interest. Unfortunately, current knowledge about these papillae characteristics is still insufficient for this purpose, as no systematic studies have been conducted on their distribution and variability, and thus important aspects of their biology and genetics are unknown. Therefore, as scientific and judicial sources have recognized for a long time $[18,35,37,39,61,62]$, it is necessary to conduct multidisciplinary studies in order to provide new information and improve the application of this technique, and thus consolidate its scientific basis.

\section{Conclusions}

We have confirmed the non-equiprobability of different minutiae types in two population samples, and have found significant topological, finger and sex differences.

We have demonstrated, for the first time, the existence of significant differences in minutiae frequencies between populations, independently from main the pattern type. These differences were present both between the two Argentinian populations studied (Ramal and Puna-Quebrada), and between each of these and a Spanish sample. 
Further research is required in order to increase our knowledge about the variability of these characteristics in human populations, in order to facilitate comparison and application in probabilistic calculation of identity. To this end, we recommend the standardization of nomenclature criteria and the adoption of clear and precise definitions to minimize subjectivity when applied.

\section{Acknowledgements}

The authors are grateful to research assistants E. L. Alfaro Gómez, B. C. Farfán, V. Pintado, E. Romero, C. Rodríguez Pacho, L. E. Hernández-Hurtado, J.L. Rodríguez-Villalba, J. L. Nieva, and J. Comendeiro for their help in this work, and to the anonymous reviewers for their valuable suggestions which have contributed to enhancement of the quality of the paper. This work was supported in part by the Agencia Española de Cooperación Internacional para el Desarrollo (AECID) under project A/01575/07, and in part by the University Institute of Investigation on Police Sciences under project IUICP/PI2007/008.

\section{References}

[1] H. Cummins, C. Midlo, Finger Prints Palms and Soles, Dover Publications Inc., New York, 1961.

[2] C. Champod, C. Lennard, P. Margot, M. Stoilovic, Fingerprints and Other Ridge Skin Impressions, 33, CRC Press, Washington, 2004.

[3] D. Ashbaugh, Quantitative-Qualitative Friction Ridge Analysis, CRC Press, Boca Raton, Florida, 1999.

[4] W.J. Babler, Prenatal communalities in epidermal ridge development, in: N.M. Durhan, C.C. Plato (Eds.), Trends in Dermatoglyphic Research, Kluwer Academic Publishers, Netherlands, 1991, pp. 54-68.

[5] H. Seidenberg-Kajabova, V. Pospisilova, V. Vranakova, I. Varga, An original histological method for studying the volar skin of the fetal hands and feet, Biomed. Pap. Med. Fac. Univ. Palacky Olomouc. Czech. Repub. 154 (3) (2010) 211-218.

[6] D.Z. Loesch, Quantitative Dermatoglyphics: Classification Genetics and Pathology, Oxford University Press, Oxford, 1983.

[7] T.J. David, Distribution, age and sex variation of the mean epidermal ridge breadth, Hum. Hered. 31 (1981) 279-282.

[8] M.H. Crawford, R. Duggirala, Digital dermatoglyphic patterns of Eskimo and Amerindian populations: relationships between geographic, dermatoglyphic, genetic and linguistic distances, Hum. Biol. 64 (1992) 683-704.

[9] J. Blangero, Population structure analysis using polygenic traits: estimation of migration matrices, Hum. Biol. 62 (1990) 27-48.

[10] B. Schaumann, M. Alter, Dermatoglyphics in Medical Disorders, Springer-Verlag, New York, 1976.

[11] L. Fañanás, P. Moral, J. Bertranpetit, Quantitative dermatoglyphics in schizophrenia: study of family history subgroups, Hum. Biol. 62 (1990) 421-427.

[12] A. Rosa, M.J. Cuesta, V. Peralta, A. Zarzuela, F. Serrano, A. Martínez-Larrea, L. Fañanás, Dermatoglyphic anomalies and neurocognitive deficits in sibling pairs discordant for schizophrenia spectrum disorders, Psychiatry Res. 137 (3) (2005) 215-221.

[13] J. Dankmeijer, J.M. Waltman, A.G. Wilde, Biological foundations for forensic identifications based on fingerprint, Acta Morphol. Neerl. Scand. 18 (1980)67-83.

[14] IEEGFI Method for Fingerprint Identification, 29th European Regional Conference, Interpol European Expert Group on Fingerprint Identification II: May 17-19, 2000, Reykjavik, 2007. http://www.interpol.int/public/Forensic/fingerprints/WorkingParties/IEEGFI/ieegfi.asp (accessed 20.07.2011).

[15] Scientific Working Group on Friction Ridge Analysis, Study and Technology (SWGFAST), et al. The Fingerprint Sourcebook, National Institute of Justice, USA, 2011. https://www.ncjrs.gov/pdffiles1/nij/225320.pdf (accessed 25.05.12).

[16] F. Galton, Finger Prints, MacMillan, London, 1892.

[17] E. Gutiérrez-Redomero, V. Galera, J.M. Martínez, C. Alonso, Biological variability of the minutiae in the fingerprints of a sample of the Spanish population, Forensic Sci. Int. 172 (2007) 98-105.

[18] Expert Working Group on Human Factors in Latent Print Analysis, Latent Print Examination and Human Factors: Improving the Practice Through a Systems Approach, U.S. Department of Commerce, National Institute of Standards and Technology, 2012

[19] D. Stoney, J. Thornton, A critical analysis of quantitative fingerprint individuality models, J. Forensic Sci. 31 (4) (1986) 1187-1216.

[20] D.A. Stoney, Measurement of fingerprint individuality, in: H.C. Lee, R.E. Gaensslen (Eds.), 2nd ed., Advances in Fingerprint Technology, CRC Press, New York, 2001, pp. 327-387.

[21] S.N. Srihari, H. Srinivasan, Individuality of Fingerprints: Comparison of Models and Measurements, Center of Excellence for Document Analysis and Recognition, Department of Computer Science and Engineering University at Buffalo, The State University of New York, Buffalo NY, USA, 2007.

[22] C. Neumann, C. Champod, R. Puch-Solis, N.M. Egli, A. Anthonioz, D. Meuwly, A. Bromage-Griffiths, Computation of likelihood ratios in fingerprint identification for configurations of three minutiae, J. Forensic Sci. 51 (6) (2006) 1255-1266.
[23] C. Neumann, C. Champod, R. Puch-Solis, N.M. Egli, A. Anthonioz, A. BromageGriffiths, Computation of likelihood ratios in fingerprint identification for configurations of any number of minutiae, J. Forensic Sci. 52 (1) (2007) 54-64.

[24] C. Neumann, I.W. Evett, J.E. Skerrett, I. Mateos-García, Quantitative assessment of evidential weight for a fingerprint comparison I. Generalization to the comparison of a mark with set of ten prints from a suspect, Forensic Sci. Int. 207 (1) (2011) 101-105.

[25] N.M. Egli, C. Champod, P. Margot, Evidence evaluation in fingerprint comparison and automated fingerprint identification systems - modelling within finger variability, Forensic Sci. Int. 167 (2007) 189-195.

[26] P. Margot, E. German, Fingerprint identification breakout meeting, in: J. Almog, E. Springer (Eds.), Proceedings of the International Symposium on Fingerprint Detection and Identification, Ne'urim, Israel, June 26-30, 1995: Israel National Police, (1996), p. p. 21.

[27] I.W. Evett, R.L. Williams, A Review of the sixteen points fingerprint standard in England and Wales, J. Forensic Ident. 46 (1996) 49-73.

[28] D. Grieve, Possession of truth, J. Forensic Ident. 46 (5) (1996) 521-528.

[29] C. Champod, I.W. Evett, A probabilistic approach to fingerprint evidence, J. Forensic Ident. 51 (2001) 101-122.

[30] Daubert v. Merrel Dow Pharmaceuticals, Inc., 509 U.S. 579; No. 92-102, 1993.

[31] R.B. Stacey, A report on the erroneous fingerprint individualization in the Madrid Train bombing case, J. Forensic Ident. 54 (6) (2004) 706-718.

[32] M.J. Saks, J.J. Koehler, The coming paradigm shift in forensic identification science, Science 309 (2005) 892-895.

[33] B. Schiffer, C. Champod, The potential (negative) influence of observational biases at the analysis stage of fingermark individualization, Forensic Sci. Int. 167 (2007) 116-120.

[34] R. Dror, Rosenthal, Meta-analytically quantifying the reliability and bias ability of forensic experts, J. Forensic Sci. 53 (4) (2008) 901-903.

[35] National Research Council, Strengthening Forensic Science in the United States: A Path Forward, The National Academies Press, Washington, DC, 2009.

[36] J.R. Vanderkolk, Examination process, in: SWGFAST, et al. (Eds.), The Fingerprint Sourcebook, National Institute of Justice, USA, 2011, pp. 1-26 (chapter 9).

[37] G. Langenburg, Scientific research supporting the foundations of friction ridge examinations, in: SWGFAST, et al. (Eds.), The Fingerprint Sourcebook, National Institute of Justice, USA, 2011, pp. 1-31 (chapter 14).

[38] E. Gutiérrez-Redomero, C. Alonso-Rodríguez, L.E. Hernández-Hurtado, J.L. Rodríguez-Villalba, Distribution of the minutiae in the fingerprints of a sample of the Spanish population, Forensic Sci. Int. 208 (2011) 79-90.

[39] D.L. Faigman, J.M.J. Saks, J. Sanders, E.K. Cheng, Modern Scientific Evidence: Standards Statistics and Research Methods, Thomson West, 2008.

[40] J.E. Dipierri, E. Alfaro, V. Martinez Marignac, G. Bailliet, C.M. Bravi, C. Cejas, N.O. Bianchi, Paternal directional matting in two Amerindian subpopulation located at different altitude in Northwest of Argentina, Hum. Biol 79 (6) (1998) 1001-1010.

[41] J.E. Dipierri, E. Alfaro, J.A. Peña, C. Jacques, J.M. Dugoujon, GM, KM inmunoglobulin allotypes and other serum genetic markers (HP, GC, PI and TF) among south American populations living at different altitude (Jujuy province, Argentina) Admixture estimates, Hum. Biol. 72 (2) (2000) 305-319.

[42] J. Aase, R.B. Lyons, Technique for recording dermatoglyphics, Lancet 1 (1971) 432-433.

[43] F.A. Barberá, J.V. de Luis-Turégano, 3rd ed., Policía Científica Titant Lo Blanch, Valencia, Spain, 1993.

[44] C. Champod, Reconnaissance automatique et analyse statistique des minuties sur les empreintes digitales, Ph.A. Thesis 1, Institut de Police Scientifique et de Criminologie, Université de Lausanne, 1996.

[45] Figueras, Dermatoglifos, Bibliografía, Departamento de Antropología de la, Universidad de Coimbra, Portugal, 1993.

[46] H.K. Kumbnani, Dermatoglyphics: a review, in: V. Bhasin, M.K. Bhasin (Eds.), Anthropology Today, 3, Scope and Applications, Kamla-Raj Enterprises, 2007, pp. 285-295.

[47] F. Santamaría Beltran, A new method for evaluating ridge characteristics, Fingerprint Ident. Mag. 36 (3-8) (1955) 16-18.

[48] C.R. Kingston, Probabilistic Analysis of Partial Fingerprint Patterns. Ph.D. Dissertation, Department of Criminology, University of California, Berkeley, 1964.

[49] S.R. Gupta, Statistical survey of ridge characteristics, Int. Crim. Polic. Rev. 218 (1968) $130-134$

[50] C. Steffens, Vergleichende Untersuchungen der Minutien der Fingerbeerenmuster bei Familien und eineiigen Zwillingspaaren, Anthropol. Anz. 29 (1965) 234-249.

[51] J.W. Osterburg, T. Parthasarathy, T.E.S. Raghavan, S. Sclove, Development of a mathematical formula for the calculation of fingerprint probabilities based on individual characteristics, J. Am. Stat. Assoc. 72 (1977) 772-778.

[52] S.L. Sclove, The occurrence of fingerprint characteristics as a two dimensional process, J. Am. Stat. Assoc. 74 (1979) 588-595.

[53] C.H. Lin, The similarity of fingerprints and the development of a single fingerprint filing and searching system, Master's Science Ph.A. Thesis, University of Illinois, Chicago, 1981.

[54] D.A. Stoney, J.L. Thornton, A systematic study of epidermal ridge minutiae, J. Forensic Sci. 32 (1987) 1182-1203.

[55] C. Champod, P. Margot, Computer assisted analysis of minutae occurrences on fingerprints, in: J. Almog, E. Springer (Eds.), Proceedings of the International Symposium on Fingerprint Detection and Identification, Ne'urim, Israel, June 2630, 1995: Israel National Police, (1996), pp. 305-318.

[56] N.C. Sarkar, Finger Ridge minutiae: Classification Distribution and Genetics, Anthropological Survey of India, Calcutta, 2004.

[57] S.A. Cole, Grandfathering evidence: fingerprint admissibility ruling from Jennings to Llera Plaza and back again, Am. Crim. Law Rev. 41 (2004) 1189-1276. 
[58] R. Garruto, C. Plato, C. Hoff, M. Newman, D. Gajdusek, P. Baker, Characterization and distribution of dermatoglyphic features in Eskimo and North, Central, and South American Indian populations, Birth Defects Orig. 15 (1979) 277-334.

[59] D. Demarchi, A. Marcellino, Dermatoglyphic relationships among South Amerindian populations, Hum. Biol. 70 (1998) 579-596.
[60] O.R. Baca, L. Del Valle Mendoza, N.A. Guerrero, Dermatoglyphics of a high altitude Peruvian population and interpopulation comparisons, High Alt. Med. Biol. 2 (1) (2001) 31-40.

[61] A. Jamieson, A. Moenssens, Wiley Encyclopedia of Forensic Science, John Wiley and Sons Ltd., United Kingdom, 2009.

[62] L. Spinney, The fine print, Nature 464 (2010) 344-346. 